\title{
Ontogenia foliar de três espécies de Erythroxylum P. Browne (Erythroxylaceae) ocorrentes no Cerrado ${ }^{1}$
}

\author{
ANGELA C. BIERAS ${ }^{2,3}$ e MARIA DAS GRAÇAS SAJO ${ }^{2}$
}

(recebido: 5 de fevereiro de 2003; aceito: 23 de outubro de 2003)

\begin{abstract}
Foliar ontogeny of three species of Erythroxylum P. Browne (Erythroxylaceae) from Cerrado). Leaves of Erythroxylum campestre, E. nanum, and E. tortuosum have been studied in different developmental stages in order to describe the leaf ontogeny and the structure of scars found in mature blades of Erythroxylum. The marginal growth of the leaves is of the "median submarginal" type. At early stages, intense activity in the adaxial meristem leads to the formation of a crest on this surface, while the laminar portion has an involuted aspect, due to the activity of the marginal meristem. The stomata develop at the same time as the mesophyll layers and the final expansion of the blade results from an intercalary growth. Blade scars were not observed during ontogeny. When present these scars appear to result from shallow injuries parallel to the midrib on the abaxial surface.
\end{abstract}

Key words - blade scar, Erythroxylaceae, Erythroxylum, foliar ontogeny

RESUMO - (Ontogenia foliar em três espécies de Erythroxylum P. Browne (Erythroxylaceae) ocorrentes no Cerrado). Com o objetivo de descrever a ontogenia foliar e natureza das cicatrizes, encontradas em lâminas adultas de Erythroxylum, foram analisadas as folhas de Erythroxylum campestre, E. nanum e E. tortuosum, em diferentes estágios de desenvolvimento. Para as três espécies, verificou-se a ocorrência de um crescimento foliar marginal do tipo "submarginal mediano". No início do desenvolvimento do órgão, a atividade do meristema adaxial é intensa e leva à formação de uma saliência nessa face, enquanto que a porção laminar se desenvolve de forma involuta, devido à atividade do meristema marginal. Os estômatos se diferenciam junto com as camadas do mesofilo e a expansão final do órgão é dada por um crescimento intercalar. Durante a ontogenia não foi registrado o aparecimento de cicatrizes laminares que, quando presentes, se assemelham a injúrias superficiais, dispostas na face inferior e paralelamente à nervura principal.

Palavras-chave - cicatriz laminar, Erythroxylaceae, Erythroxylum, ontogenia foliar

\section{Introdução}

O gênero Erythroxylum reúne representantes arbóreos, arbustivos e subarbustivos, de folhas e ramos alternos ou opostos. As folhas são glabras, inteiras, membranáceas, cartáceas ou coriáceas e possuem estípulas interpeciolares, persistentes ou caducas, de tamanho e consistência variável que podem ser fimbriadas ou enervadas e apresentar ápice bi, tri ou não setuloso. O gênero é formado por 250 espécies, distribuídas nas regiões tropicais e subtropicais do mundo (Amaral Junior 1980), sendo que para o Brasil é descrita a ocorrência de 130 espécies, em ambientes florestais e de Cerrado lato sensu. No Cerrado, alguns Erythroxylum são representantes bastante conhecidos por apresentarem súber espesso e galhos retorcidos.

Várias espécies do gênero possuem propriedades medicinais, sendo as populares cocas (E. coca Lamk. e

1. Parte da dissertação de mestrado de Angela C. Bieras, IB/UNESP, Rio Claro, SP

2. Universidade Estadual Paulista, Instituto de Biociências, Departamento de Botânica, Caixa Postal 199, 13506-900 Rio Claro, SP.

3. Autor para correspondência: acbieras@rc.unesp.br
E. novogranatense (D.Morris) Hieron.) e suas variedades as mais conhecidas e estudadas, devido à presença de alcalóides em suas folhas. Trabalhos como os de Bohm et al. (1982), Plowman (1982) e Rury \& Plowman (1983) salientam a dificuldade para delimitar corretamente os representantes de coca que são muitas vezes tratados como sendo único (E. coca). Tais estudos, juntamente com os realizados por Ballard (1926a, b, c), Machado (1972) e Rury (1981), apontam inúmeras características morfo-anatômicas foliares, úteis na delimitação dos táxons do gênero. Dentre elas, destaca-se a presença de duas linhas laterais, paralelas à nervura principal, que aparecem na face abaxial e se estabelecem durante o desenrolar das folhas involutas das cocas cultivadas (E. coca e E. novogranatense) e de E hardinii E. Machado, E. gracilipes Peyr. e E. paraense Peyr. (Machado 1972). Em algumas espécies de Erythroxylum do Cerrado também se observam cicatrizes, na face abaxial, que seguem um curso paralelo à nervura principal e se assemelham às linhas laterais, presentes nas folhas das cocas e demais espécies.

Com o objetivo de descrever a ontogenia foliar e a natureza das cicatrizes, encontradas em lâminas adultas de Erythroxylum, foram analisadas as folhas de 
E. campestre A. St.-Hil., E. nanum A. St.-Hil. e E. tortuosum Mart., em diferentes estágios de desenvolvimento.

\section{Material e métodos}

Ramos caulinares, com folhas em diferentes estágios de desenvolvimento, foram coletados nos remanescentes de Cerrado dos municípios de Botucatu e Itirapina, Estado de São Paulo. O material testemunha encontra-se depositado no Herbário Rioclarense (HRCB), sob as seguintes especificações: Erythroxylum campestre A. St.-Hil. (HRCB 36723), E. nanum A St.-Hil. (HRCB 36719) e E. tortuosum Mart. (HRCB 36718). Os estudos foram realizados utilizando-se oito espécimes de E. campestre e de E. nanum e cinco espécimes de E. tortuosum.

O material foi fixado em FAA 50 (Johansen 1940) e estocado em álcool 50\% glicerinado. Para o estudo da superfície foliar utilizaram-se folhas adultas, portadoras de cicatrizes, que foram secas, entre lâminas de vidro, montadas em stubs, metalizadas num metalizador Desk II Denton Vacuum e analisadas e fotografadas num Microscópio Eletrônico de Varredura Jeol JSM - 5410.

Para o estudo da ontogenia folhas, em diferentes estágios de desenvolvimento, foram desidratadas em série etanólica (Johansen 1940) e incluídas em parafina (Berlyn \& Miksche 1976 apud Kraus \& Arduin 1997, Johansen 1940 apud Kraus \& Arduin 1997, Sass 1951 apud Kraus \& Arduin 1997). Os cortes transversais, realizados com o auxílio de micrótomo rotativo, foram corados com Fucsina Básica e Azul de Astra (Roeser 1972 apud Kraus \& Arduin 1997) e montados em lâminas permanentes, utilizando resina Entellan. Os resultados foram registrados através de fotomicrografias, obtidas num fotomicroscópio Olympus BX 40.

\section{Resultados e Discussão}

Observando-se os ápices dos ramos das três espécies de Erythroxylum estudadas, notam-se folhas de filotaxia alterna (figuras 1,2 ) que, em E. tortuosum (figura 2), se dispõem quase que oposta e/ou verticiladamente devido ao encurtamento dos entrenós. Apesar dessa variação, todas as folhas estudadas se desenvolvem de forma idêntica e por essa razão a ontogenia é descrita de forma única para as três espécies.

Nas figuras 3-6 observam-se cortes transversais de primórdios foliares em estágio inicial de desenvolvimento. Nessa fase, a atividade meristemática na região adaxial é intensa, levando à formação de uma saliência (figuras 3, 4, 6). A forma dessa saliência foi usada como característica auxiliar na delimitação de representantes do gênero por Ballard (1926a, b, c), Machado (1972), Rury (1981), Bohm et al. (1982) e

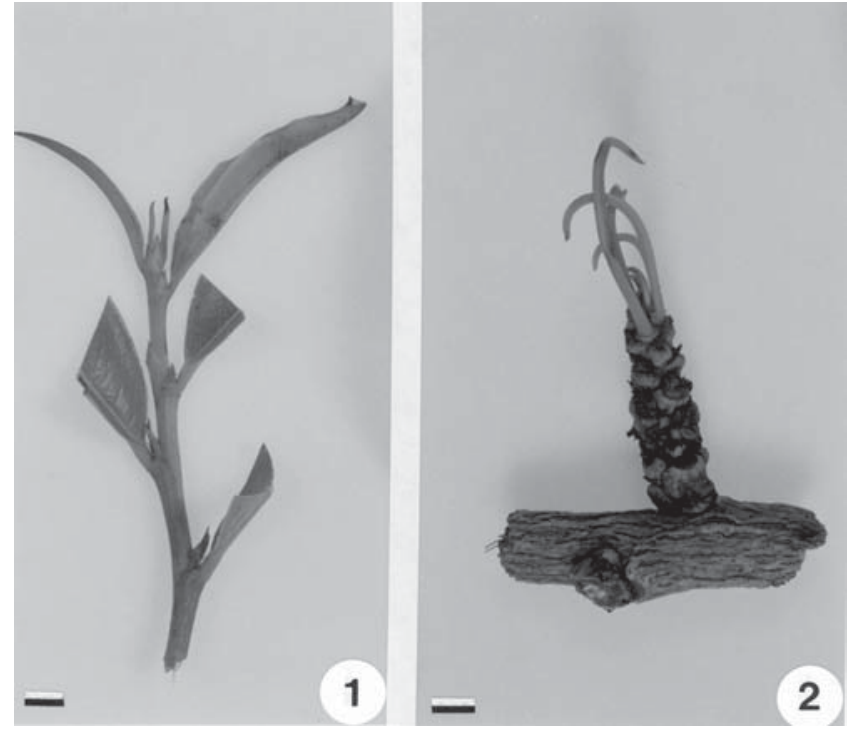

Figuras 1-2. Ápices de ramo de Erythroxylum. 1. E. nanum. 2. E. tortuosum. Barras $=0,5 \mathrm{~cm}$.

Figures 1-2. Branch apex of Erythroxylum. 1. E. nanum. 2. E. tortuosum. Bars $=0.5 \mathrm{~cm}$.

Rury \& Plowman (1983). Nas figuras 3 e 4 observa-se, também, o início da formação do limbo, que se dá com a diferenciação de dois meristemas marginais, voltados para a face adaxial do eixo foliar. Nessas regiões, observa-se uma faixa periférica de células provenientes das iniciais marginais, que se dividem anticlinalmente (em relação à superfície do órgão), dando origem à protoderme (figuras 5,6). Abaixo das iniciais marginais são encontradas as iniciais submarginais que se dividem anticlinal e periclinalmente, formando as camadas adaxial (figuras 5,6), mediana (figuras 5,6) e abaxial (figuras 5,6) do mesofilo. Esse tipo de crescimento marginal, o qual resulta em um mesofilo com três camadas distintas, foi classificado por Hara (1957) como "submarginal mediano". Nesse caso, os feixes vasculares laterais se originam de células da camada mediana, que se diferenciam em procâmbio (Hara 1959), como pode ser visto na figura 5 . A protoderme, na face abaxial, se divide em ritmo mais intenso que na face adaxial, promovendo o enrolamento da lâmina, de forma involuta. A uma certa distância da margem, a camada abaxial sofre uma divisão periclinal (figuras 5,6 ) que se repete pouco mais adiante (figura 6), acompanhando o enrolamento da lâmina (figuras 3-6). Machado (1972), Rury (1981) e Mcwhorter \& Ouzts (1994) observaram que as folhas de E. coca e E. novogranatense se desenvolvem de forma involuta e atribuíram a essa forma de desenvolvimento o aparecimento das linhas nas lâminas foliares dessas espécies. Entretanto nenhum estudo de ontogênese foliar foi realizado por esses 
autores. Nessa fase pode ser, ainda, observado que o sistema vascular da futura nervura principal (eixo foliar) já se encontra em diferenciação (figuras 3,4 ), exibindo a forma que irá adquirir na folha adulta. Esse sistema vascular se origina de células de procâmbio que se diferenciam em continuidade com o procâmbio do traço foliar, conforme descrito por Esau (1974) e Fahn (1982), para folhas de dicotiledôneas em geral.

Um estágio subseqüente, do desenvolvimento foliar, encontra-se representado nas figuras 7-10. Nessa fase, o limbo se encontra em intenso crescimento intercalar, ocasionando seu aumento em extensão (figura 7). Também ocorre aumento em espessura, devido a divisões periclinais sofridas pela camada mediana (figura 8). Próximos à futura nervura principal, notamse os estômatos recém formados (figura 9) e células do mesofilo em estágio avançado de diferenciação, confirmando as observações de Tetley (1932 apud Popham 1966), que relaciona o aparecimento dos estômatos com a formação de espaços intercelulares,

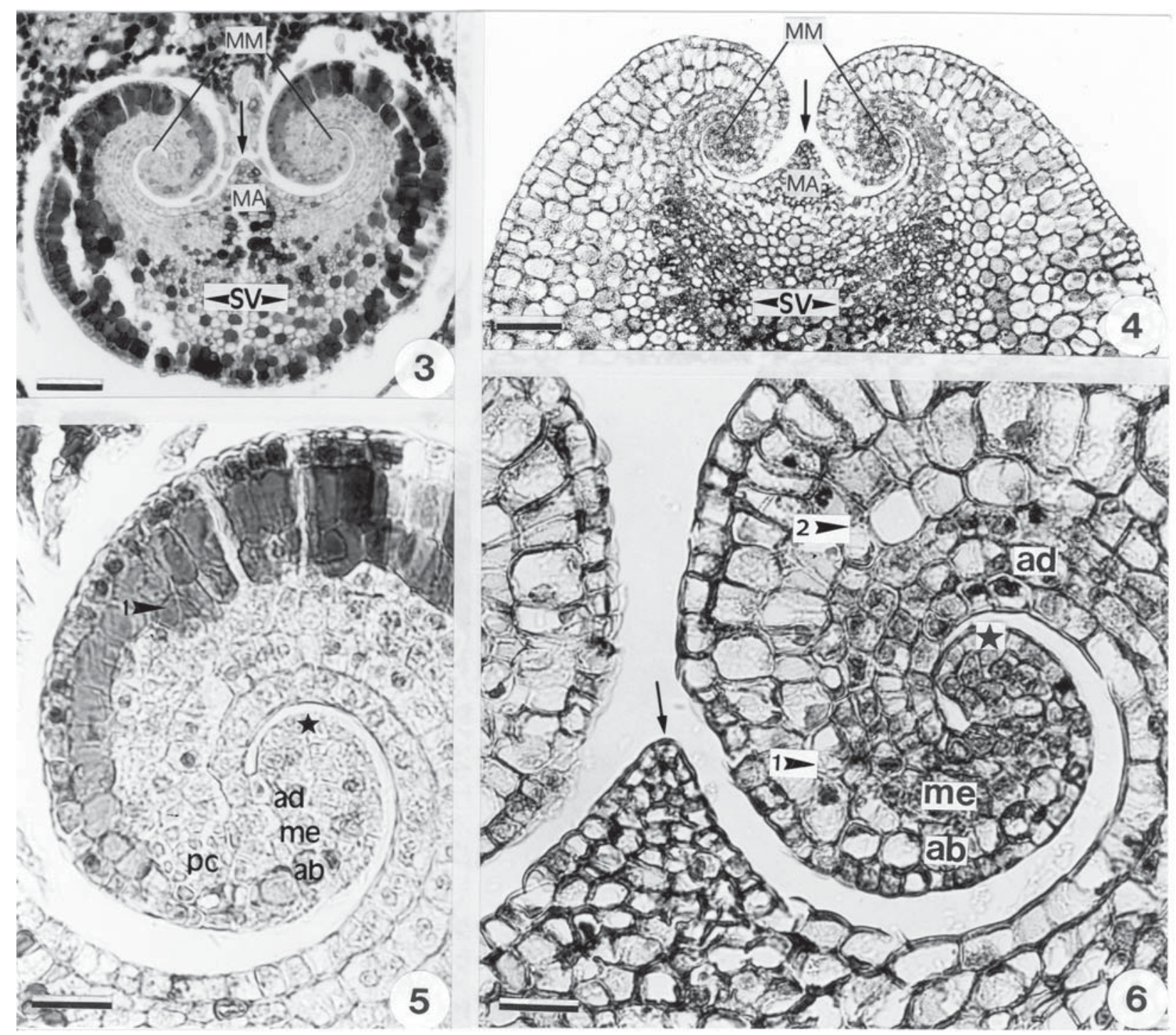

Figuras 3-6. Secções transversais de primórdios foliares de Erythroxylum em estágio inicial de desenvolvimento. 3, 5. E. nanum. 4, 6. E. tortuosum. (Seta = saliência da região adaxial; estrela = protoderme; ponta de seta $1=$ primeira divisão periclinal da camada abaxial; ponta de seta 2 = segunda divisão periclinal da camada abaxial; $\mathrm{MM}=$ meristema marginal; $\mathrm{MA}=$ meristema adaxial; $\mathrm{SV}=$ sistema vascular; $\mathrm{ad}=$ camada adaxial; $\mathrm{me}=$ camada mediana; $\mathrm{ab}=$ camada abaxial; $\mathrm{pc}=$ procâmbio). Barras $=70 \mu \mathrm{m}$ $(3,4) ; 20 \mu \mathrm{m}(5,6)$.

Figures 3-6. Cross-sections of leaf primordia of Erythroxylum at early stages of development. 3, 5. E. nanum. 4, 6. E. tortuosum. (Arrow $=$ prominence on the adaxial surface; star = protodermis; arrowhead 1 = first periclinal division on the abaxial layer; arrow head $2=$ second periclinal division on the abaxial layer; $\mathrm{MM}=$ marginal meristem; $\mathrm{MA}=$ adaxial meristem; $\mathrm{SV}=\mathrm{vascular}$ system; $\mathrm{ad}=$ adaxial layer; $\mathrm{me}=$ median layer; $\mathrm{ab}=$ abaxial layer; $\mathrm{pc}=$ procambium $) . \operatorname{Bars}=70 \mu \mathrm{m}(3,4) ; 20 \mu \mathrm{m}(5,6)$. 
ou seja, com a fase final de diferenciação dos tecidos internos. Nessa mesma região, observa-se uma pequena e precoce atividade cambial, que origina novos elementos vasculares e promove a união entre os feixes colaterais (figura 10), fazendo com que o sistema vascular adquira o formato característico que terá na folha adulta.

A última fase do desenvolvimento foliar é a da diferenciação dos tecidos do mesofilo observada nas figuras 11 e 12. Essa diferenciação tem início com o alongamento, no sentido periclinal, das células que irão formar o parênquima paliçádico (camada adaxial), acompanhado por divisões anticlinais (figura 12). Ao mesmo tempo, as células epidérmicas adjacentes crescem, no sentido anticlinal, fazendo com que várias células de parênquima paliçádico se conectem a uma mesma célula epidérmica (figura 12). As células da
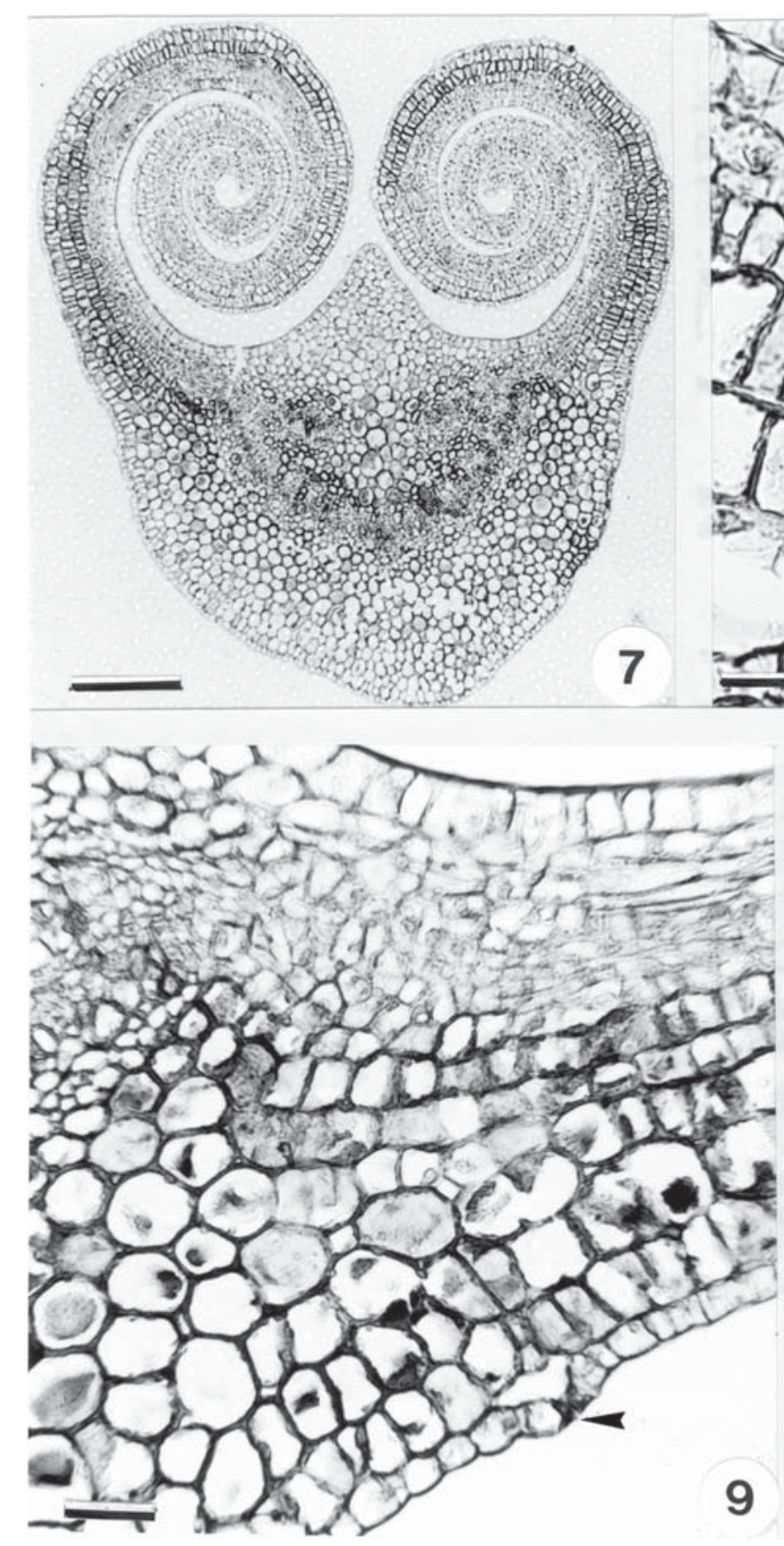
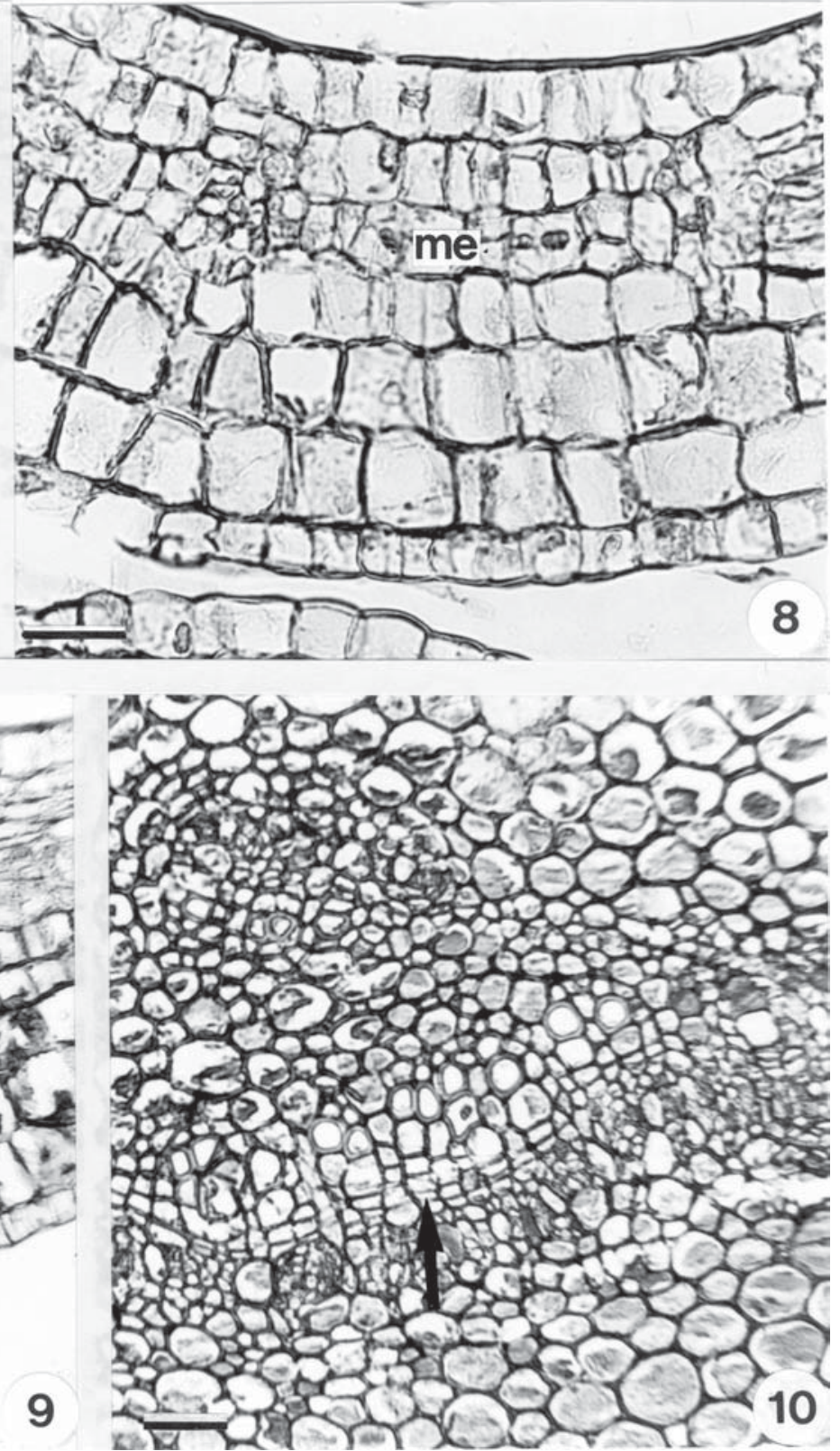

Figuras 7-10. Secções transversais de primórdios foliares de Erythroxylum tortuosum, em estágio intermediário de desenvolvimento. 7. Aspecto geral. 8-9. Mesofilo. 10. Detalhe do tecido vascular da nervura principal. (Ponta de seta = estômato; seta $=$ câmbio vascular; me $=$ camada mediana). Barras $=200 \mu \mathrm{m}(7) ; 20 \mu \mathrm{m}(8) ; 30 \mu \mathrm{m}(9,10)$.

Figures 7-10. Cross sections of the leaf primordia of Erythroxylum tortuosum at an intermediate stage of development. 7. General aspect. 8-9. Mesophyll. 10. Developing vascular tissues of the midrib. (arrowhead $=$ stomata; arrow $=$ vascular cambium; me = median layer). Bars $=200 \mu \mathrm{m}(7) ; 20 \mu \mathrm{m}(8) ; 30 \mu \mathrm{m}(9,10)$. 
camada mediana também se dividem anticlinalmente e se diferenciam em parênquima intervenal de aspecto lacunoso (figura 12). A camada abaxial, formada por células volumosas e alongadas no sentido anticlinal, irá dar origem a células de parênquima lacunoso organizadas compactamente (figura 12). Também nessa fase é possível observar a formação de extensões de bainha parenquimáticas ao redor dos feixes vasculares laterais (figura 12).

A partir desse ponto, tanto o mesofilo quanto a nervura principal encontram-se definidos, sendo observado apenas o crescimento intercalar, que é o responsável pela expansão completa da folha.

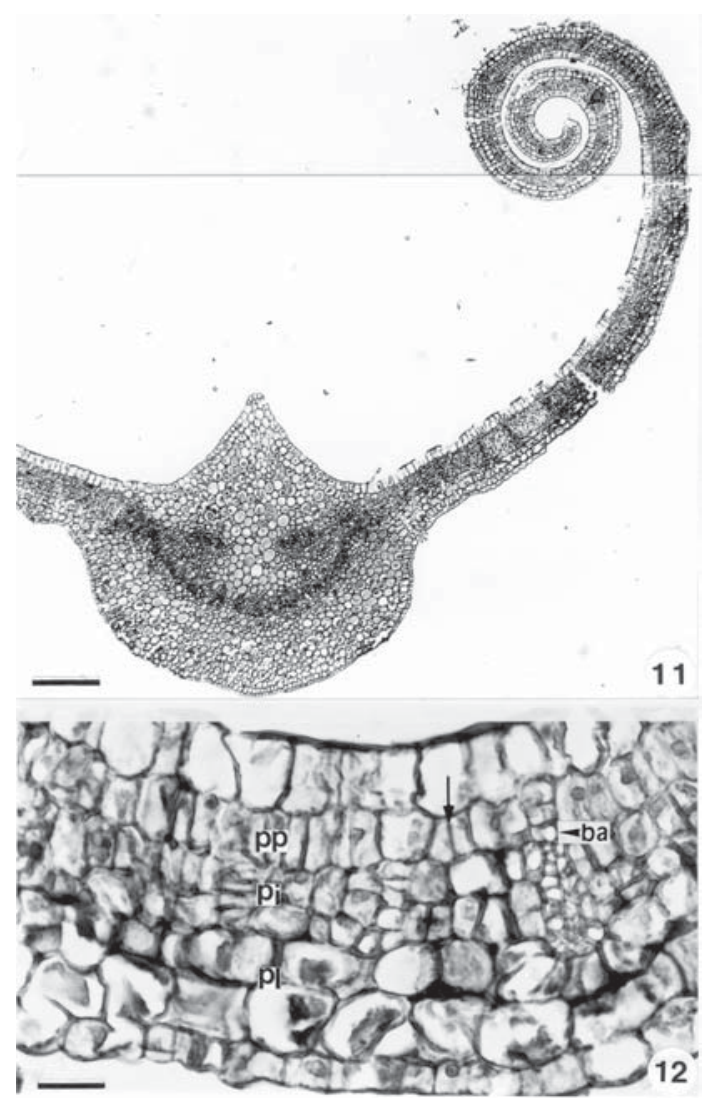

Figuras 11-12. Erythroxylum tortuosum. 11. Secção transversal do primódio foliar em estágio final de desenvolvimento. 12. Detalhe do mesofilo. (Seta = células de parênquima paliçádico conectadas a uma célula epidérmica; $\mathrm{pp}=$ parênquima paliçádico; $\mathrm{pi}=$ parênquima intervenal de aspecto lacunoso; $\mathrm{pl}$ = parênquima lacunoso; $\mathrm{ba}=$ extensão parenquimática de bainha, num feixe vascular lateral). Barras $=200 \mu \mathrm{m}(11) ; 20 \mu \mathrm{m}(12)$.

Figures 11-12. Erythroxylum tortuosum. 11. Cross section of a leaf primordium at a late developmental stage. 12. Detail of mesophyll. $($ Arrow $=$ palisade cells linked to one epidermal cell; $\mathrm{pp}=$ palisade parenchyma; $\mathrm{pi}=$ intervenal spongy parenchyma; $\mathrm{pl}=$ spongy parenchyma; $\mathrm{ba}=$ parenchymatous extension of the vascular bundle sheaths). Bars $=200 \mu \mathrm{m}$ (11); $20 \mu \mathrm{m}$ (12).
Uma representação esquemática, baseada nos estudos de Hara (1957), do tipo de crescimento marginal, para as espécies estudadas, pode ser vista na figura 13 .

Como observado nas figuras 14 e 15, as folhas adultas das espécies estudadas possuem cicatrizes

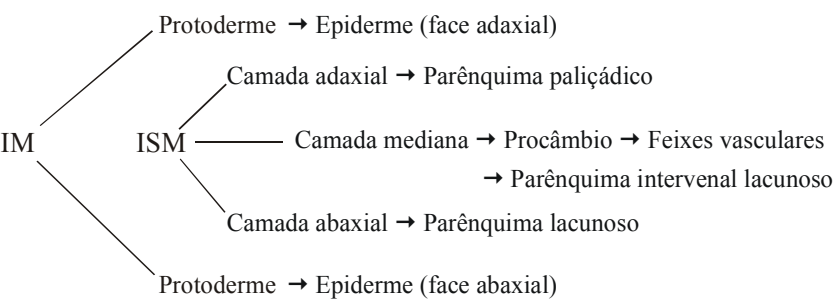

Figura 13. Esquema do crescimento marginal tipo "submarginal mediano" apresentado pelas folhas de Erythroxylum $(\mathrm{IM}=$ inicial marginal $\mathrm{e}$ ISM $=$ inicial submarginal).

Figure 13. Flow diagram of "submarginal median" developmental sequence, observed in Erythroxylum leaves (IM = marginal initial and ISM $=$ submarginal initial).

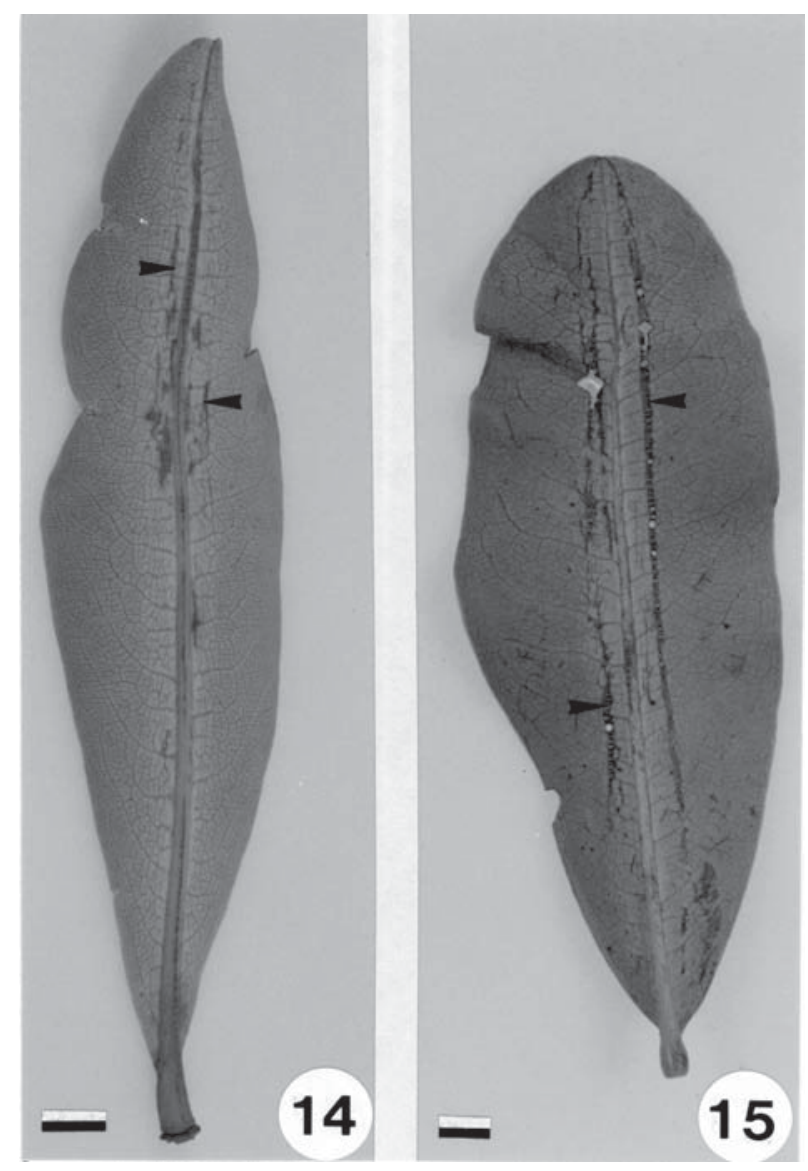

Figuras 14-15. Folhas de Erythroxylum contendo cicatrizes na face abaxial (ponta de seta). 14. E. tortuosum. 15. E. nanum. Barras $=0,5 \mathrm{~cm}$.

Figures 14-15. Erythroxylum leaves with abaxial scars (arrowhead). 14. E. tortuosum. 15. E. nanum. Bars $=0.5 \mathrm{~cm}$. 
laminares, na face abaxial. Em alguns casos elas são tênues e não aparecem em toda a extensão da lâmina (figura 14); em outros, as cicatrizes são bastante evidentes (figura 15) e se dispõem de forma paralela ao longo da nervura principal.

O corte transversal de uma folha adulta de E. nanum, com cicatriz laminar na face abaxial, pode ser visto na figura 16. Nota-se que, na região correspondente à cicatriz, a epiderme e células subepidérmicas estão rompidas e obliteradas e ocorre um tecido de cicatrização de origem parenquimática (figura 17). Nas figuras 18 e 19 estão ilustradas as cicatrizes da superfície foliar de E. campestre. Aqui também se nota que a epiderme se encontra danificada em determinados pontos, expondo o tecido mais interno.
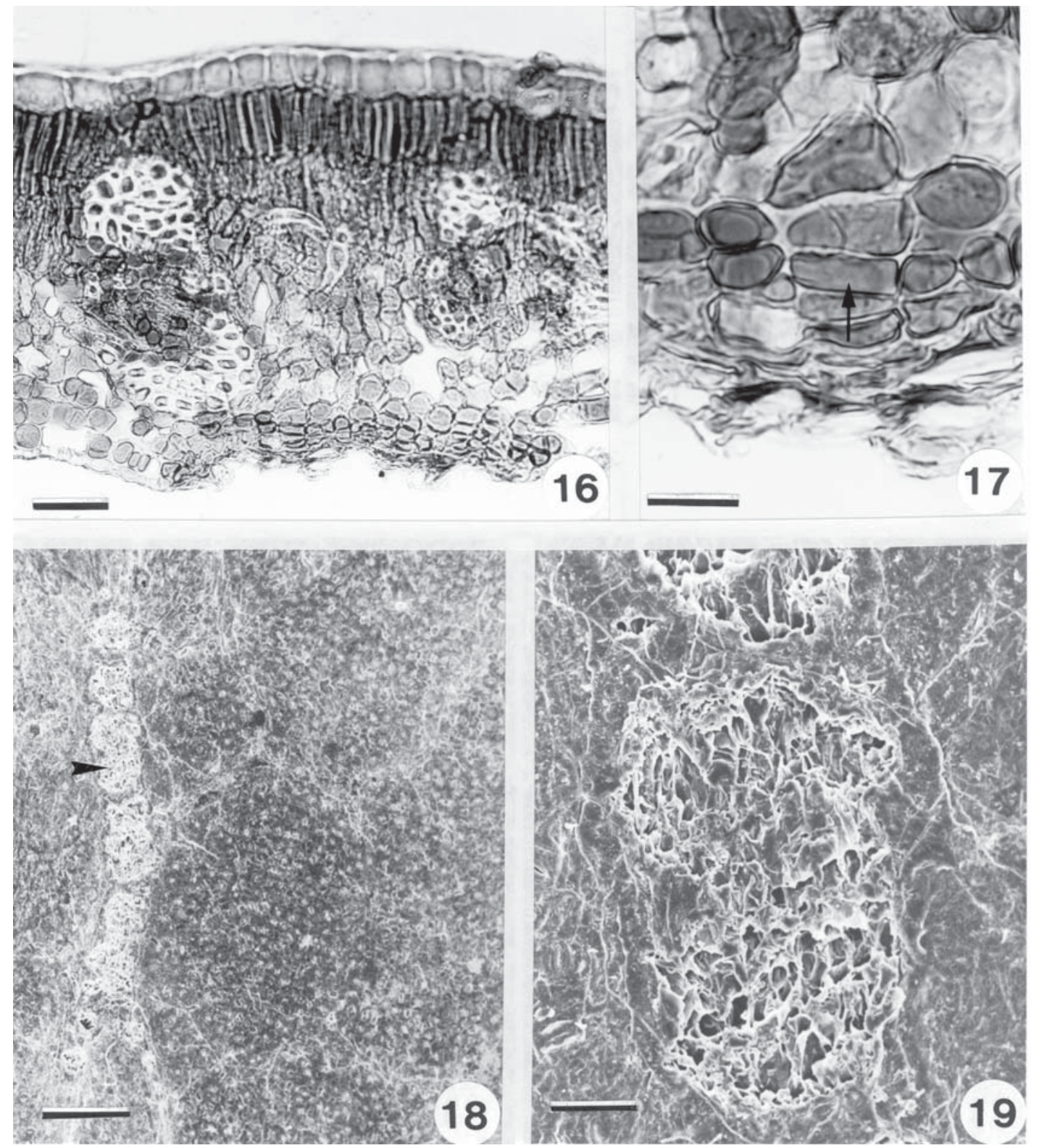

Figuras 16-17. Secções transversais da lâmina foliar de Erythroxylum nanum. 16. Mesofilo, na região da cicatriz. 17. Detalhe do tecido de cicatrização sob a área lesionada correspondente à cicatriz (seta). Figuras 18-19. Eletromicrografia de varredura da folha de Erythroxylum campestre, em vista frontal. 18. Face abaxial, mostrando a cicatriz (ponta de seta). 19. Detalhe da cicatriz. Barras $=70 \mu \mathrm{m}(15,18) ; 20 \mu \mathrm{m}(16) ; 375 \mu \mathrm{m}(17)$.

Figures 16-17. Erythroxylum nanum leaf in cross section. 16. Mesophyll at the scar region. 17. Detail of the scar tissue (arrow) under the damaged region. Figures 18-19. Scanning electromicrograph of Erythroxylum campestre leaves in frontal view. 18. Abaxial surface showing a scar (arrowhead). 19. Detail of scar. Bars $=70 \mu \mathrm{m}(15,18) ; 20 \mu \mathrm{m}(16) ; 375 \mu \mathrm{m}(17)$. 
Durante a ontogenia não foi notado aparecimento de cicatrizes, nem indícios de que estas se formem devido ao modo de desenrolar das folhas. Isso contraria o sugerido por Ballard (1926a, b, c), Machado (1972) e Rury (1981) - para as linhas foliares das espécies de coca, de Erythroxylum hardinii, E. gracilipes e de E. paraense - que, segundo os autores, aparecem como resultado do desenrolar das folhas involutas durante o desenvolvimento desses órgãos, representando protuberâncias de colênquima dispostas paralelamente à nervura principal. Porém, como citado anteriormente, os autores não realizaram qualquer estudo ontogenético com as folhas dessas espécies. Segundo Machado (1972), as linhas podem desaparecer durante o desenvolvimento das folhas e são revestidas por células epidérmicas mais desenvolvidas que as demais e portadoras de paredes mais delgadas. As cicatrizes laminares das folhas aqui estudadas são injúrias superficiais e sob estas ocorre um tecido de cicatrização de origem subepidérmica. Por essas razões acredita-se que elas não sejam homólogas às linhas laterais das folhas das cocas cultivadas e demais espécies.

Embora a origem das cicatrizes laminares não seja conhecida, é improvável que elas estejam relacionadas com o processo de desenvolvimento e abertura das folhas involutas. No entanto, quando presentes, elas são sempre paralelas à nervura principal e ocorrem somente na face abaxial, como as linhas laterais das folhas de outros representantes do mesmo gênero.

Agradecimentos - Os autores agradecem o suporte financeiro do Projeto Biota - Fapesp (Processo 2000/12469-3). A.C. Bieras, agradece as bolsas concedidas pela Capes e pelo $\mathrm{CNPq}$.

\section{Referências bibliográficas}

AMARAL JUNIOR, A. 1980. Eritroxiláceas. In Flora ilustrada catarinense (R. Reitz, ed.). Herbário Barbosa Rodrigues, Itajaí, parte 1, 64p.
BALLARD, C.W. 1926a. Structural variations in Erythroxylum leaves. Journal of the American Pharmaceutical Association 15:343-359.

BALLARD, C.W. 1926b. Structural variations in Erythroxylum leaves. Journal of the American Pharmaceutical Association 15:433-453.

BALLARD, C.W. 1926c. Structural variations in Erythroxylum leaves. Journal of the American Pharmaceutical Association 15:533-549.

BOHM, B.A., GANDERS, F.R. \& PLOWMAN, T. 1982. Biosystematic and evolution of cultivated coca (Erythroxylaceae). Systematic Botany 7:121-133.

ESAU, K. 1974. Anatomia das plantas com sementes. Editora Edgard Blücher, São Paulo.

FAHN, A. 1982. Anatomia Vegetal. Ediciones Piramidales, Madrid.

HARA, N. 1957. On the types of the marginal growth in dicotyledonous foliage leaves. Botanical Magazine Tokyo 70:108-114.

HARA, N. 1959. Marginal growth of leaves. Nature 183:1409-1410.

JOHANSEN, D.A. 1940. Plant Microtechnique. McGraw-Hill, New York.

KRAUS, J.E. \& ARDUIN, M. 1997. Manual básico de métodos em morfologia vegetal. Editora da Universidade Rural, Rio de Janeiro.

MACHADO, E.C. 1972. El gênero Erythroxylon en el Peru. Raymondiana 5:5-101.

MCWHORTER, C.G. \& OUZTS, C. 1994. Leaf surface morphology of Erythroxylum sp. and droplet spread. Weed Science 42:18-26.

PLOWMAN, T. 1982. The identification of coca (Erythroxylum species): 1860-1910. Botanical Journal of the Linnean Society 84:329-353.

POPHAN, R.A. 1966. Laboratory manual of plant anatomy. C.V. Mosby Company, Sant Louis.

RURY, P.M. 1981. Systematic anatomy of Erythroxylum P. Browne: practical and evolutionary implications for the cultivated cocas. Journal of Ethnopharmacology 3:229-263.

RURY, P.M. \& PLOWMAN, T. 1983. Morfological studies of archeological and recent coca leaves (Erythroxylum spp.). Botanical Museum Leaflets 29:297-341. 